\title{
Custo Total de Propriedade: adoção no setor de compras da Usina Foz de Chapecó
}

\begin{abstract}
Moacir Francisco Deimling
Doutorado em andamento em Engenharia de Produção pela Universidade Federal do

Rio Grande do Sul - UFRGS

Professor da Universidade Comunitária da Região de Chapecó - UNOCHAPECÓ Rua Senador Attílio Fontana, 591. Chapecó/SC. CEP: 89809-000

E-mail:moacir@unochapeco.edu.br
\end{abstract}

Juliano Giongo Pós-Graduação em Gestão de Produção e Logística pela Universidade Comunitária da Região de Chapecó - UNOCHAPECÓ Encarregado de Patrimônio II da Empresa Consórcio Construtor Belo Monte Avenida Trancredo Neves, 5045. Altamira/PA. CEP: 68372-901 E-mail: juliano_giongo@hotmail.com

Danuza Fátima Zanrosso Graduação em andamento em Administração pela Universidade Comunitária da Região de Chapecó - UNOCHAPECÓ Área de Recursos Humanos na empresa Auto Viação Sul Transporte de Passageiros LTDA ME SCT 480 Km 08 s/n. Distrito de Marechal Bormann. Chapecó/SC E-mail:danuzafz@unochapeco.edu.br

\section{RESUMO}

Este artigo tem como objetivo apresentar elementos relacionados com a utilização do Custo Total de Propriedade (TCO - Total Cost of Ownership) no processo de compra de uma construtora de grande porte, referente à realização da obra na usina hidrelétrica Foz do Chapecó, visando analisar e registrar o uso prático desta ferramenta. São analisados alguns itens de compra com o Custo Total de Propriedade, considerado como uma ferramenta de contabilidade gerencial que dá suporte à tomada da decisão de compra. Os dados da pesquisa foram obtidos no setor de suprimentos, especialmente, na área de compras da construtora na usina hidrelétrica Foz do Chapecó. Foram feitas entrevistas com os responsáveis pelas compras e manutenção, bem como utilizada pesquisa documental em relatórios gerenciais para obter os dados necessários às análises, caracterizando a pesquisa como um estudo de caso, de caráter descritivo e quali-quantitativo. Os principais resultados apontam para a viabilidade desta ferramenta para a tomada de decisões na área de compras.

Palavras-chaves: Custos. Compras. Suporte a decisão. Competitividade. 


\section{ABSTRACT}

This article aims to present elements of implementation of the Total Cost of Ownership (TCO) in the process of purchase of a large size construction company, referring to the implementation of work on the hydroelectric plant Foz do Chapecó, aiming to analyze and register the practical use of this tool. It presents the analysis of some purchased items with the Total Cost of Ownership, as a tool of managerial accounting that supports making the decision to purchase.The survey data were obtained from the sector of supply, especially in the purchases area of the construction company on hydroelectric plant Foz do Chapecó. It was used interviews with those responsible for purchases and maintenance, as well as documental research in managerial reports to get the data necessary for the analysis. One can characterize this work as a case study, in character descriptive and qualitative. The main results show the viability of this tool for making decisions in the purchases area.

Keyword: Costs. Purchases. Decision Making Support. Competitiveness.

\section{INTRODUÇÃO}

Atualmente as empresas buscam cada vez mais adequação às inúmeras imposições de mercado, especialmente às competitivas, uma vez que nada mais é como era há um tempo: um mercado seguro, sem turbulências. Segundo Pacheco (2006), muita coisa mudou. O atual período de turbulência pelo qual o mundo está passando, com uma competição cada vez mais intensa, exige dinamicidade em se formular caminhos alternativos para que as empresas não entrem em um ciclo de estagnação, ou até mesmo de declínio.

Nesse sentido, fica claro que as empresas (e/ou empreendimentos) enfrentam desafios cada vez maiores quando objetivam permanecer, com competência e lucro, no mercado. Para Kotler (1998) as empresas não podem mais ignorar os avanços tecnológicos e de mercados que fazem parte do mundo empresarial atual.

$\mathrm{Na}$ verdade, o que acontece é que atualmente, quando as nações do mundo (em especial no contexto econômico, que traz reflexos na organização social e política), estão sob o efeito da globalização, os consumidores transformam-se em sujeitos poderosos e as empresas, por sua vez, sentem este e outros reflexos, e buscam 
instrumentos e ferramentas para permanecerem/sobreviverem no mercado (IANNI, 1999).

Para Silva e Villar (2010, p.1),

a acirrada concorrência empresarial somada às crescentes exigências dos clientes faz com que as organizações busquem novas estratégias com o intuito de se tornarem cada vez mais eficientes e competitivas. Esta busca visa o crescimento da competência empresarial e a conquista de maiores fatias de mercado com base na redução dos custos operacionais e no aumento da qualidade dos produtos e dos serviços ofertados.

Ocorre que, aos poucos, um novo contexto econômico (globalizado) vai tomando o lugar de um sistema simples e tradicional de mercado, abrindo espaço à expressiva concorrência nos empreendimentos. Devido a extrema capacidade criativa, o homem elabora nesse contexto, segundo Kotler (1998), soluções administrativas diversas, que englobam desde análise até planejamento, implementação e controle, destacando-se nesse contexto para auxiliar nas tarefas, em primeiro lugar, o setor de compras, seguido pela gestão estratégica.

O Setor Compras, segundo Souza, Bacic e Bernardes (2009, p.47) é de importância estratégica para gerar economias para a empresa, pois "a função compras tem um papel muito importante no controle e na diminuição de custos". A gestão estratégica de custos, por sua vez, no âmbito empresarial, cresce à medida que evoluem as exigências dos consumidores e o acirramento da concorrência entre as empresas. Os empreendimentos que objetivam subsistir e crescer em um mercado cada vez mais disputado precisam desenvolver vantagem competitiva em sua atuação (MAUSS; MAGALHÃES; SOUZA, 2010).

Nesse contexto, o setor de compras mostra-se fundamental para diminuir gastos e, consequentemente, maximizar o resultado da empresa. A gestão estratégica, por sua vez, elabora/cria instrumentos e ferramentas diversas, destacando-se o Total Cost of 
Ownership (TCO) que é, segundo Lima e Leitão (2010), uma ferramenta para fazer análise dos custos diretos e indiretos, composto pelos custos orçados e não orçados.

Dentro desse contexto, este artigo tem como objetivo apresentar elementos relacionados com a utilização do Custo Total de Propriedade no processo de compra de uma construtora de grande porte, referente à obra na Usina Hidrelétrica Foz do Chapecó, visando acompanhar e registrar o uso prático desta ferramenta de gestão estratégica, considerando que esta ferramenta permite que empresas como a construtora em estudo fortaleçam/dinamizem a área de compras e, com isso, façam as compras mais vantajosas, inclusive quando se trata de produtos como: pneus; filtros (para caminhões); câmaras (para pneus); e protetor (para pneus).

Portanto, o presente estudo proporciona formulações de um modelo de custo total de propriedade que leva em consideração os principais custos envolvidos na aquisição de um determinado produto, para assim auxiliar os compradores nas decisões cotidianas. Cabe ressaltar, enfim, que esta empresa apresenta um percentual elevado de gastos com compras, competindo apenas com a folha de pagamento dos funcionários.

\section{REFERENCIAL TEÓRICO}

As empresas enfrentam desafios diversos na atual conjuntura de mercado e, entre eles, o de efetuar as melhores compras. Para auxiliar nesse processo, como ferramenta competente, se apresenta o Total Cost of Ownership (TCO).

\subsection{Histórico e Conceito do Custo Total de Propriedade (TCO)}

A Revolução Industrial trouxe um novo contexto ao modelo produtivo existente, e com ela outros setores se viram forçados a acompanhar a evolução, em especial ao controle de todo empreendimento em si, para que o mesmo realmente gerasse o tão objetivado lucro. Surge, nesse contexto, uma crescente preocupação com os custos que envolvem o processo produtivo (LUCCA; COLS, 2010). 
Dessa forma, surgem as ferramentas de auxílio na elaboração dos custos, em especial ligados à contabilidade e administração, sendo que nesta última, segundo Kotler (1998), criam-se soluções diversas para auxiliar nas tarefas. De acordo com Lima e Leitão (2010), o TCO era, a princípio, uma ferramenta para avaliar custos do setor de informática e, aos poucos, foi sendo dinamizado e estruturado para atender a toda área logística, sendo uma das mais recentes ferramentas para se custear uma parcela específica da cadeia logística (SILVA; VILLAR, 2010) para a compreensão dos custos totais de aquisição de um bem ou serviço de um fornecedor específico.

Assim, segundo Mitsutani (2006), o TCO é cada vez mais utilizado em processos de seleção e escolha, seja de um determinado produto, serviço ou tecnologia. Entretanto, o TCO requer que o comprador determine quais são os custos mais relevantes para a aquisição e/ou manutenção de um determinado bem ou serviço (BORNIA; FREIRES, 2005).

No mesmo sentido, Lima e Leitão (2010) relatam que o custo total de propriedade pode ser definido como uma abordagem complexa que requer que a organização compradora identifique todos os custos relevantes das atividades de aquisição, posse e uso de um bem ou serviço. Este autor salienta que o TCO consegue levantar o verdadeiro custo de compras, pois soma todos os elementos de custos relevantes para decisões de compras, inclusive os incorridos ao longo do processo de compra e de impactos significativos em outras funções da organização, decorridos da compra. Enfim, para este autor o TCO ajuda as organizações a obterem uma visão de longo prazo do custo de se fazer negócio, sobre a compra de um determinado produto com determinado fornecedor.

Neste contexto, Dabbys (2012) relata que o custo total de propriedade é simplesmente uma estimativa financeira de todos os custos: diretos e indiretos de aquisição, comissionamento, operação, manutenção e descarte de um produto ou sistema por um determinado período de tempo estimado.

No entanto, para Alves e Cardoso (2012), custo total de propriedade nada mais é do que o somatório dos gastos, efetivos e esperados, de aquisição e aqueles relativos 
ao transporte, instalação, propriedade, utilização, manutenção e descarte do produto adquirido, avaliados a valor presente. Mitsutani (2006) considera o TCO uma ferramenta analítica que procura avaliar os elementos que impactam ou geram custos, quando da escolha de uma nova fonte de suprimento, novo produto, tecnologia, entre outras. Assim, esta ferramenta leva em consideração todos os elementos que impactam no custo das organizações: preço, lote mínimo, condições de pagamento (custos usuais), custos de manutenção, custos de obsolescência, custo da mudança, impactos em produtividade e custos de descontinuidade (custos "escondidos"), ou seja, utiliza-se o TCO para escolhas complexas, custosas e/ou que tem impacto de longo prazo.

Assim sendo, todos os custos têm que ser considerados na hora de se fazer uma compra, considerando-se também os custos gerados pelas atividades que ocorrem antes, durante e depois do ato de aquisição de um insumo (SILVA; VILLAR, 2010), sendo uma das ferramentas mais indicadas para ser usada na hora de avaliar custos e decidir compras, inclusive de produtos diversos, como: pneus, filtros (para caminhões), câmaras (para pneus) e protetor (para pneus).

A escolha por esta ferramenta ainda tem como fator a seu favor sua objetividade, uma vez que o objetivo do TCO é obter o controle total dos custos e, dessa forma, auxiliar os gestores das empresas na avaliação dos investimentos, melhorando a estratégia e, consequentemente, tornando as empresas mais competitivas (WANTROBA, 2007). Isso porque na maioria das vezes a decisão de compra está associada ao preço mais baixo, em virtude de ser ele aquele que recai sobre a maior parte dos produtos, dele ficando excluídos apenas os de natureza intelectual e os produtos de informática (SANT ANA; ROCHA, 2006).

Portanto, a técnica de TCO é uma eficiente ferramenta de contabilidade gerencial, bem como de gerenciamento de custo estratégico e de GCS, uma vez que otimiza os processos de compra, aquisição, seleção de fornecedores e as parcerias com o mesmo, otimizando, assim, todos os custos que ocorrem na cadeia de suprimento (IGNACIO et al., 2006). 


\subsection{Aspectos e itens considerados no TOC}

O TCO é um sistema de cálculo destinado a assistir os consumidores na avaliação dos custos, assim como os benefícios relacionados à compras diversas. Para entender como funciona o TCO, é preciso compreender os aspectos da ferramenta e os itens que compõem seu processo de cálculo.

Segundo Ecos (2010), o TOC é uma ferramenta de aspecto ágil e eficiente que diminui custos e, consequentemente, maximiza lucros, pois considera todos os itens envolvidos na aquisição do bem e/ou serviço, como: custos de planejamento; custos de aquisição; custos de operação e manutenção; e custos de alienação e, ainda, avalia o retorno do investimento.

Nesse sentido, os objetivos do Custo do Ciclo de Vida (LCC)/Custo Total de Propriedade (TCO), segundo Flanagan e Normann (1983 apud KUMAR; CHATTOPADHYAY; PANNU, 2004) são:

- Para ativar as opções de investimento a ser mais efetivamente avaliados;

- Para considerar o impacto de todos os custos, em vez de apenas os custos de capital inicial;

- Para auxiliar na gestão eficaz de projetos concluídos;

- Para facilitar a escolha entre alternativas concorrentes.

Por outro lado, nesse contexto, quanto aos itens considerados (e/ou que compõem a ferramenta), cabe detalhar/especificar que o TCO de uma empresa é composto pelos custos orçados e não orçados, ou custos diretos (aqueles itens que fazem parte do centro de custo da área de sistema, tais como: software, hardware, pessoal administrativo e operacional) e custos indiretos (os custos que normalmente, na maioria das empresas não são tratados pelo orçamento, tais como: suporte, formal e informal, ao usuário final, treinamento informal, a perda de produtividade por conta da indisponibilidade (downtime) do equipamento, entre outros), visando alinhar as estratégias; otimizar processos; reduzir custos; melhorar os níveis de serviços, e, incrementar a produtividade (LIMA; LEITÃO, 2010). 
Para Wantroba (2007), os custos incluídos no TCO são: planejamento, aquisição, operação e manutenção, e alienação, levando em consideração todo o ciclo de vida do bem (e/ou serviço). Assim, compreende-se que o TCO é uma ferramenta de cálculo de custo, a fim de auxiliar na decisão de comprar (ou não comprar), que inclui em seu cálculo toda e qualquer despesa inserida no produto e no processo de aquisição/manutenção do mesmo.

\subsection{Decisão de Compras}

Compras é uma função fundamental na administração de materiais. Na opinião de Dias (2010), a área de compras deve suprir os materiais e serviços necessários para promover o funcionamento da organização, deve planejar as quantidades e satisfazer no tempo certo e com a quantidade correta, conferir se recebeu o que realmente comprou e providenciar o armazenamento das compras. Nesse sentido, as atividades realizadas pela área de compras estão compostas por objetivos que tem por intuito, segundo Gonçalves (2007, p. 243), "garantir que materiais e serviços exigidos sejam fornecidos nas quantidades corretas, com qualidade, no tempo desejado".

Existem muitos fatores que podem gerar vantagem competitiva para a organização ao comprar materiais e suprimentos. Para Ignacio et. al (2006), uma das mais importantes atividades do gerenciamento de compras é a análise dos custos, ou seja, esta análise leva a um gerenciamento adequado dos custos.

Nesse contexto, a decisão de compras, segundo Paes e Kliemann Neto (2010) é o momento decisivo em uma empresa, pois o administrador estará efetuando a aquisição de um bem/material, ou prestação de serviços e estará, em contrapartida, retirando dinheiro/capital do caixa. Inclusive, de acordo Fleury (2003), o gerenciamento de custos da cadeia de suprimentos deve ter como norteamento de ação a vantagem competitiva. Bornia (2002), por sua vez, lembra que um sistema de custos vai, primeiramente, ajudar a decidir o que deve ser levado em consideração (qual informação é importante) para efetuar a compra, para em seguida analisar como a informação será obtida e analisada. 
O comprador decide, então, pelo sistema tradicional ou por sistema que carece de mais dados e maiores análises, como o TCO. O sistema tradicional, no geral, apenas considera os dados mais visíveis e transparentes do ciclo de vida na visão do consumidor, e o processo embasado no sistema TCO considera os itens intrínsecos do custo.

Para Bezerra e Nascimento (2010), a principal utilização dos conceitos que envolvem o TCO está no fato de que este controle irá propiciar uma melhor utilização dos recursos da empresa impactando de forma positiva no seu resultado, significando compras que, ao final, geram menor custo, otimizando o valor do setor de compras e, finalmente, um resultado final com maior lucro.

Por outro lado, Dabbys (2012) enfatiza que a maioria das organizações que tiveram sucesso na otimização do TCO tem líderes que exigem a cooperação entre grupos funcionais, pois estes reconhecem que a otimização de custos é uma função das operações de manutenção, e o departamento de compras deve trabalhar para o objetivo comum de reduzir os custos totais. Enfim, o TCO além de revelar-se uma ferramenta eficiente no setor de compras da empresa, possibilita que as empresas estreitem o relacionamento com fornecedores considerados estratégicos (LIMA; LEITÃO, 2010) e, por isso, o mesmo pode ser adotado em qualquer tipo de empresa.

\section{METODOLOGIA}

A empresa em estudo refere-se a uma construtora de grande porte, que atua no contexto da engenharia e construção, trabalhando em grandes obras, tanto no mercado interno como externo, e a implantação do Custo Total de Propriedade (TCO) no setor de compras nesta empresa mostra-se como um interessante processo a ser analisado.

Nesse sentido, o presente artigo pode ser caracterizado como um estudo de caso, com pesquisa participativa. Visando elaborar conhecimento profundo e amplo sobre o objeto/tema/assunto elaborou-se a pesquisa adotando um procedimento metodológico exploratório, pois esta objetiva "conhecer a variável de estudo tal como se 
apresenta, seu significado e o contexto onde ela se insere" (PIOVESAN; TEMPORINI, 2010, p. 02).

A pesquisa foi desenvolvida no setor de suprimentos, especificamente na área de compras da empresa em estudo, particularmente da obra da Usina Hidrelétrica Foz do Chapecó, situada nas imediações do Município de Águas de Chapecó (SC), sendo que na construção da mesma já passaram aproximadamente 8.144 profissionais de diversas áreas, incluindo o setor (área) compras.

Este estudo de caso envolveu o processo de compra de quatro produtos, sendo: pneus; filtros (para caminhões); câmaras (para pneus); e protetor (para pneus) e, nesse contexto, o levantamento de dados da pesquisa propriamente dita envolveu diversos profissionais desta obra, como borracheiros, encarregado geral e encarregados da lubrificação, entre outros, com levantamento por meio de entrevista informal.

A coleta de dados foi realizada mediante observação participante, acompanhando a rotina do setor de suprimentos, área de compras, no período de fevereiro a junho de 2010. Os dados envolvem diferentes períodos de levantamento de aquisição de produtos, somando no total doze meses (um ano) para cada produto, e foram obtidos de relatórios do sistema da empresa. Os dados coletados foram analisados e interpretados através de metodologia qualitativa e quantitativa, com o objetivo de obter um resultado amplo e abrangente.

\section{ANÁLISE DOS RESULTADOS}

O setor de suprimentos da empresa em estudo, da obra da Barragem Foz de Chapecó, encontra-se atualmente em funcionamento nesta obra, tendo seis colaboradores que atuam no setor de compras. A eles compete o compromisso de elaborar/promover aquisições que supram as necessidades da obra e cumpram os objetivos da empresa e dos que a contratam para atender um pedido/obra de seu interesse e/ou necessidade. 
Considerando o padrão de trabalho e os procedimentos estabelecidos neste setor da empresa e, também, o desempenho das suas funções com competência, estes colaboradores receberam Instrução de Trabalho, internamente conhecida como I.T., na qual consta dados diversos do setor de suprimentos, enfocando inclusive como funciona o processo de compras. A I.T. atualmente em uso no setor de suprimentos, área de compras, foi desenvolvida em 19 de junho do ano de 2007, pela Superintendência de Procurement, diretoria de engenharia e gestão da UT 005 de Vila Olímpia, constituindo-se em propriedade das empresas da Unidade de Negócios de Infra-Estrutura da Área de Engenharia \& Construção da empresa em estudo, conforme se observa na Figura 1.

\begin{tabular}{|c|c|c|c|c|}
\hline & \multicolumn{2}{|c|}{ PROCEDIMENTO PADRÃO } & Pàgina & $1 / 12$ \\
\hline & \multirow{3}{*}{\multicolumn{2}{|c|}{ Compra de Materiais e Bens não Controlados }} & Revisào & 1 \\
\hline & & & Data & $01 / 11 / 04$ \\
\hline & & & & $\begin{array}{l}\text { icaçăo: } \\
\mathrm{P} / 1119\end{array}$ \\
\hline \multicolumn{2}{|c|}{ Responsável: Gerencia de Estratégia de Suprimentos } & \multicolumn{3}{|c|}{ Aprovaçăo: Superintendencia de Procurement } \\
\hline
\end{tabular}

\begin{tabular}{|c|c|l|}
\hline \multicolumn{3}{|c|}{ Histórico } \\
\hline Data & Revisão & \multicolumn{1}{c|}{ Modificação } \\
\hline $01 / 11 / 04$ & 0 & $\begin{array}{l}\text { Revisão geral para adequação do Sistema de Gestão da UN - Infra-Estrutura } \\
\text { (Em substituição ao GSU/PP/353 - Aquisição e Gerenciamento de Materiais e Bens não } \\
\text { controlados nas Unidades de Traballo) }\end{array}$ \\
\hline $30 / 03 / 2007$ & 1 & $\begin{array}{l}\text { Revisão geral para adequação ao formato estabelecido pelo Procedimento \$GP/PP/008 - } \\
\text { Formataç̃o de Documentos }\end{array}$ \\
\hline & & \\
\hline & & \\
\hline & &
\end{tabular}

Figura 1 - Instrução de Trabalho (IT)

As I.T. têm como objetivo a orientação da metodologia a ser empregada na aquisição de produtos e o comprador sempre deve consultar este documento para saber como proceder em sua prática de compras, bem como para sanar dúvidas. Cabe 
salientar que a primeira tarefa de um novo colaborador é inteirar-se das I.T. em uso e validade naquele momento.

Cada procedimento (especialmente autorizações), e/ou compra propriamente dita, precisam ser registradas conforme orientação das U.T. Na sequência, apresentase uma lista de materiais (LM), identificando os materiais a serem cotados, sendo: pneus, filtro, câmara e protetor, com o objetivo de demonstrar o uso da ferramenta TCO.

\subsection{Materiais adquiridos}

Para a aquisição de pneus os dados foram levantados no período de um ano, sendo: 01 de maio de 2009 a 01 de maio de 2010, num total de 05 pedidos/ordem de compras, conforme se verifica na Tabela 1.

Tabela 1 - Dados para aquisição de pneus

\begin{tabular}{|c|c|c|c|c|}
\hline \multicolumn{5}{|c|}{ PROCESSO DE COMIRA - CUSTO TOTAL DE PROPR } \\
\hline & Código: & \multicolumn{3}{|c|}{795040} \\
\hline & Perío do de Avaliação: & \multicolumn{3}{|c|}{12 MESES $(01 / 05 / 2009$ à 01/05/2010) } \\
\hline \multicolumn{2}{|r|}{ Quantidade: } & \multicolumn{3}{|c|}{$361 \mathrm{UND}$ ADES } \\
\hline & & Fornecedor A & Fornecedor B & Fornecedor $\mathrm{C}$ \\
\hline 1 & Preço de Aquisição & $\mathrm{R} \$ 1.272,00$ & $\mathrm{R} \$ 1.490,00$ & $\mathrm{R} \$ 1.970,00$ \\
\hline 2 & Custo Logístico & $\mathrm{R} \$ 53,56$ & - & $\mathrm{R} \$ 39,60$ \\
\hline 3 & Custo Estoque & NA & NA & NA \\
\hline 4 & Custo Qualidade & $\mathrm{R} \$ 0,00$ & $\mathrm{R} \$ 747,00$ & $\mathrm{R} \$ 788,00$ \\
\hline 5 & Custo Manutenção & $\mathrm{R} \$ 754,00$ & $\mathrm{R} \$ 754,00$ & $\mathrm{R} \$ 754,00$ \\
\hline 6 & Custo de descarte & NA & NA & NA \\
\hline & CUSTO TOTAL & $\mathrm{R} \$ 2.079,56$ & $\mathrm{R} \$ 2.991,00$ & $\mathrm{R} \$ 3.551,60$ \\
\hline & OTAL NO PERIODODE 12 MESES & $\mathrm{R} \$ 459.192,00$ & $\mathrm{R} \$ 537.890,00$ & $\mathrm{R} \$ 711.170,00$ \\
\hline
\end{tabular}

Em relação à aquisição de filtro, os dados também foram levantados no período de um ano, de 01 de maio de 2009 a 01 de maio de 2010, totalizando 05 pedidos/ordens de compra. 
Custo total de propriedade: adoção no setor de compras da Usina Foz de Chapecó Moacir Francisco Deimling, Juliano Giongo, Danuza Fátima Zanrosso

Tabela 2 - Dados para aquisição de filtro

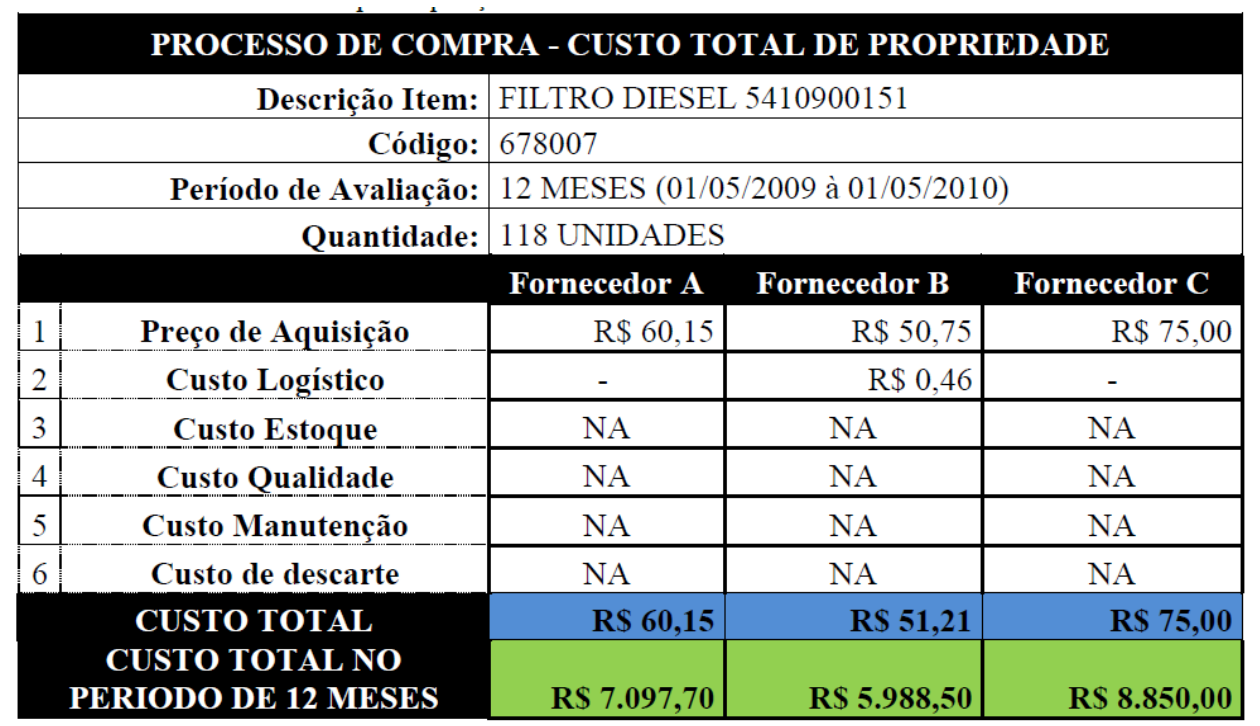

N.A.= Não Aplicado (motivo da não aplicação: valores serem idênticos).

Para a aquisição de Câmara (de ar), os dados também foram levantados no período de um ano, sendo de 16 de abril de 2009 a 16 de abril de 2010, também totalizando 05 pedidos/ordens de compra.

Tabela 3 - Dados para aquisição de Câmara (de ar)

\begin{tabular}{|r|l|}
\hline \multicolumn{2}{|c|}{ PROCESSO DE COMPRA - CUSTO TOTAL DE PROPRIEDADE } \\
\hline Descrição Item: & CÂMARA AR PNEU 1200R20 \\
\hline Código: & 702722 \\
\hline Período de Avaliação: & 12 MESES (16/04/2009 à 16/04/2010) \\
\hline Quantidade: & 602 UNIDADES \\
\hline
\end{tabular}

\begin{tabular}{|c|c|c|c|c|}
\hline & Fornecedor A & Fornecedor B & Fornecedor C \\
\hline 1 & Preço de Aquisição & $\mathrm{R} \$ 104,00$ & $\mathrm{R} \$ 98,00$ & $\mathrm{R} \$ 83,54$ \\
\hline 2 & Custo Logístico & $\mathrm{R} \$ 6,25$ & - & $\mathrm{R} \$ 2,75$ \\
\hline 3 & Custo Estoque & NA & NA & $\mathrm{NA}$ \\
\hline 4 & Custo Qualidade & NA & NA & NA \\
\hline 5 & Custo Manutenção & NA & NA & NA \\
\hline 6 & Custo de descarte & NA & NA & NA \\
\hline & CUSTO TOTAL & RS 110,25 & RS 98,00 & RS 86,29 \\
\hline & $\begin{array}{l}\text { CUSTO TOTAL NO } \\
\text { PERIODO DE } 12 \text { MESES }\end{array}$ & RS 73.008,00 & RS 68.796,00 & RS 58.645,08 \\
\hline
\end{tabular}

N.A.= Não Aplicado (motivo da não aplicação: valores serem idênticos). 
Em relação à aquisição de protetor, os dados foram levantados no período de um ano, sendo de 02 de abril de 2009 a 02 de abril de 2010, totalizando 09 pedidos/ordens de compra.

Tabela 4 - Dados para aquisição de protetor (de câmara)

\begin{tabular}{|c|c|c|c|}
\hline Descrição Item: & \multicolumn{3}{|c|}{ PROTETOR CÂMARA AR 20R } \\
\hline Código: & \multicolumn{3}{|l|}{81111} \\
\hline Período de Avaliação: & \multicolumn{3}{|c|}{12 MESES (02/04/2009 à 02/04/2010) } \\
\hline \multirow[t]{2}{*}{ Quantidade: } & \multicolumn{3}{|l|}{550 UNIDADES } \\
\hline & Fornecedor A & Fornecedor B & Fornecedor C \\
\hline Preço de Aquisição & $\mathrm{R} \$ 14,00$ & $\mathrm{R} \$ 22,00$ & $\mathrm{R} \$ 16,37$ \\
\hline Custo Logístico & $\mathrm{R} \$ 1,87$ & - & $\mathrm{R} \$ 0,71$ \\
\hline Custo Estoque & $\mathrm{NA}$ & $\mathrm{NA}$ & NA \\
\hline Custo Qualidade & NA & NA & NA \\
\hline Custo Manutenção & NA & NA & $\mathrm{NA}$ \\
\hline Custo de descarte & NA & NA & NA \\
\hline CUSTO TOTAL & RS 15,87 & RS 22,00 & RS 17,08 \\
\hline $\begin{array}{l}\text { CUSTO TOTAL NO } \\
\text { PERIODO DE } 12 \text { MESES }\end{array}$ & RS 4.900,00 & RS 7.700,00 & RS 5.729,50 \\
\hline
\end{tabular}

N.A.= Não Aplicado (motivo da não aplicação: valores serem idênticos).

Estes são os dados levantados dos produtos. Em seguida procedeu-se a análise com a ferramenta Total Cost of Ownership - TCO.

\subsection{Aplicação do TCO}

O item pneu novo 1200E20G3770 TR-GOO - código 795040, normalmente é adquirido conforme normas e critérios de compra, onde se efetua o processo de cotação com três marcas distintas : A, B e C. A projeção de utilização de cada pneu é estimada em 1800 horas. Há de se salientar, nesse contexto, que alguns fatores influenciam nesta vida útil do pneu, como: volume de carga, velocidade de tráfego, condições de pista e a qualidade do recape, sendo que no período de um ano foram adquiridos 361 pneus, totalizando $\mathrm{R} \$ 459.192,00$.

Este levantamento contou com a colaboração/ajuda do setor de manutenção, em entrevistas (informais) com encarregados da borracharia, que forneceram dados 
imprescindíveis para calcular o custo/hora de cada pneu/marca. Com estes dados em mãos, verificaram-se as quantidades de horas rodadas por equipamento, que revelou que a durabilidade estabelecida da empresa é de 1.800 horas para cada pneu. Esse dado oportunizou calcular o custo de qualidade de cada marca.

No produto especificado, utilizando-se a ferramenta do TCO, a escolha pelo fornecedor A é acertada, conforme demonstrado, pois além de possuir o melhor preço de aquisição, apresenta menor custo de qualidade, tendo assim, maior durabilidade em horas por pneu, conforme se verifica no Gráfico 1.

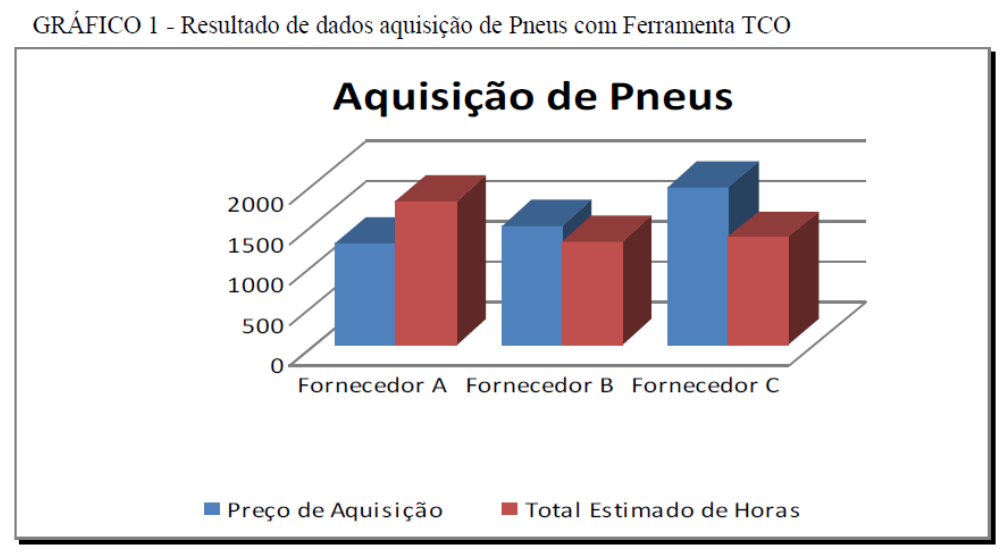

Fonte: Dados da pesquisa.

O item filtro diesel, 5410900151 - código 678007 normalmente é adquirido conforme normas e critérios de compra, efetuando-se o processo de cotação com três marcas distintas: A, B e C.

Em entrevista (informal) com o encarregado do Setor/Área de lubrificação, verificou-se que as três marcas atendem nos quesitos durabilidade/manutenção e qualidade, sendo que a durabilidade de cada filtro de óleo é de $2.500 \mathrm{hrs} /$ máquinas trabalhando. Cabe salientar que nesse contexto as três marcas pesquisadas não conseguem atingir esse padrão de 2.500 horas, que foi estabelecido pelo setor competente pela manutenção preventiva dos equipamentos. Portanto, para o presente estudo, a projeção de utilização de cada filtro foi estimada em 2.500 horas. 
No período de um ano o setor de compras da Construtora, Unidade Barragem Foz do Chapecó comprou 118 filtros, totalizando $R \$ 7.097,70$. Para facilitar a compreensão apresenta-se o Gráfico 2. Utilizando-se a ferramenta TCO, verificou-se que o Fornecedor B possui a mesma qualidade e o custo de aquisição é menor e, assim, a partir desta análise mostrou-se mais viável a concretização das compras com o fornecedor B.

Para o item Câmara (de ar) levantaram-se dados de nove pedidos/ordens de compra, totalizando 602 unidades. O item câmara (de ar) pneu 1200 R20 - código 702722 foi adquirido conforme normas e critérios de compra, considerando o processo de cotação com três marcas distintas: A, B e C.

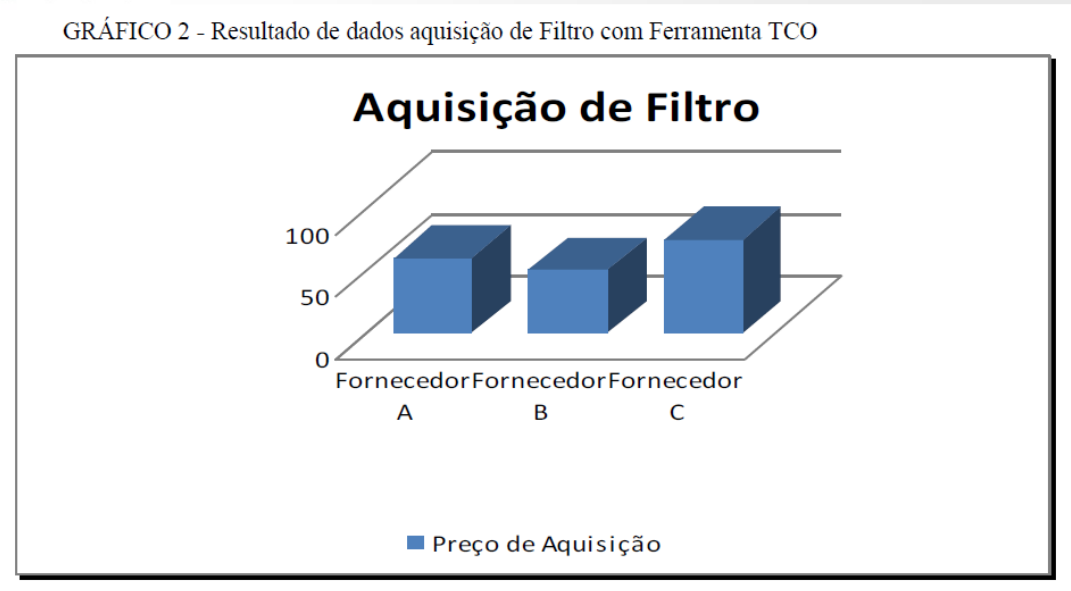

Fonte: Dados da pesquisa.

No levantamento de dados dos pneus contou-se com a colaboração/ajuda da pessoa ligada ao setor de manutenção, mais precisamente os encarregados e os líderes da borracharia e operadores dos equipamentos. Em entrevista informal, estes informaram que a durabilidade/qualidade e manutenção das três marcas citadas são as mesmas, tanto para a Câmara (de ar), como para o Protetor (de Pneus). Esse resultado revela que tanto câmara, como protetor apresentam a mesma qualidade/durabilidade e manutenção, ficando como critério de compra o valor de aquisição e frete. 
Também no período de um ano, o setor de compras da empresa, Unidade Barragem Foz do Chapecó, levantou dados referente à compra/aquisição de 602 câmaras (de ar). Os dados constam no gráfico a seguir:

GRÁFICO 3 - Resultado aquisição de Câmaras (de ar) com Ferramenta TCO

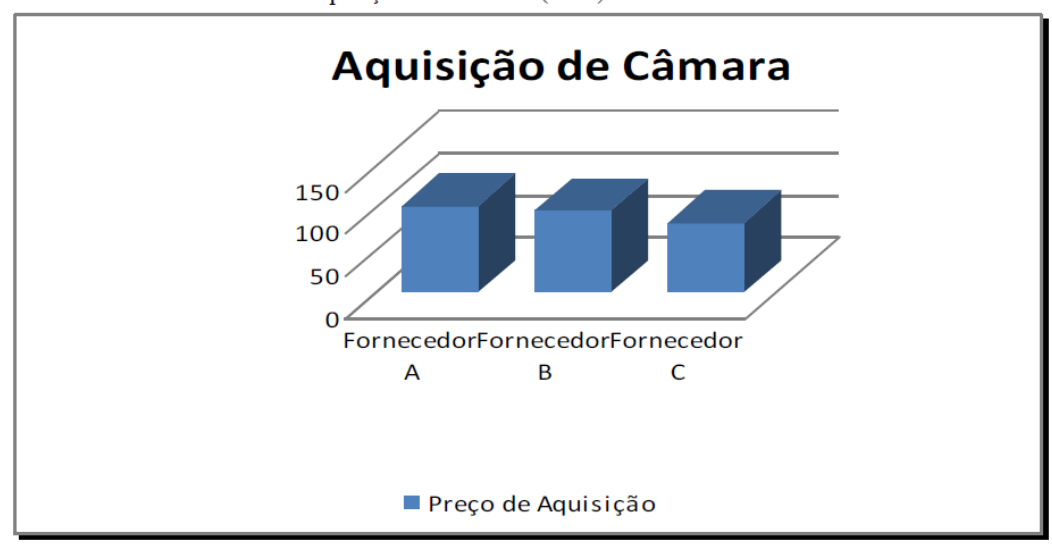

Fonte: Dados da pesquisa.

Ao se analisar todos os dados obtidos no levantamento de compra/aquisição de 602 câmaras, estes revelam que tanto a câmara como o protetor apresentam a mesma qualidade/durabilidade e manutenção, ficando como critério final de compra outros dados, como o valor de aquisição e frete. Nesse contexto, a escolha recai sobre 0 fornecedor C. Para o item Protetor (de pneus) levantou-se dados de nove pedidos/ordens de compra, totalizando 550 unidades.

Como no levantamento de dados dos pneus e câmaras esse levantamento também contou com a colaboração/ajuda do pessoal ligado ao setor de manutenção, mais precisamente os encarregados e líderes da borracharia e operadores dos equipamentos, sendo que os mesmos, em entrevista informal, informaram que a durabilidade/qualidade e manutenção das três marcas citadas são as mesmas, tanto para a Câmara (de ar), como para o Protetor (de Pneus). Nesse caso considera-se como critério de compra o valor de aquisição e frete. 
No período de um ano o setor de compras da Construtora, Unidade Barragem Foz do Chapecó, levantou dados referente à compra/aquisição de 550 de protetores (de câmaras). Os dados constam no Gráfico 4.

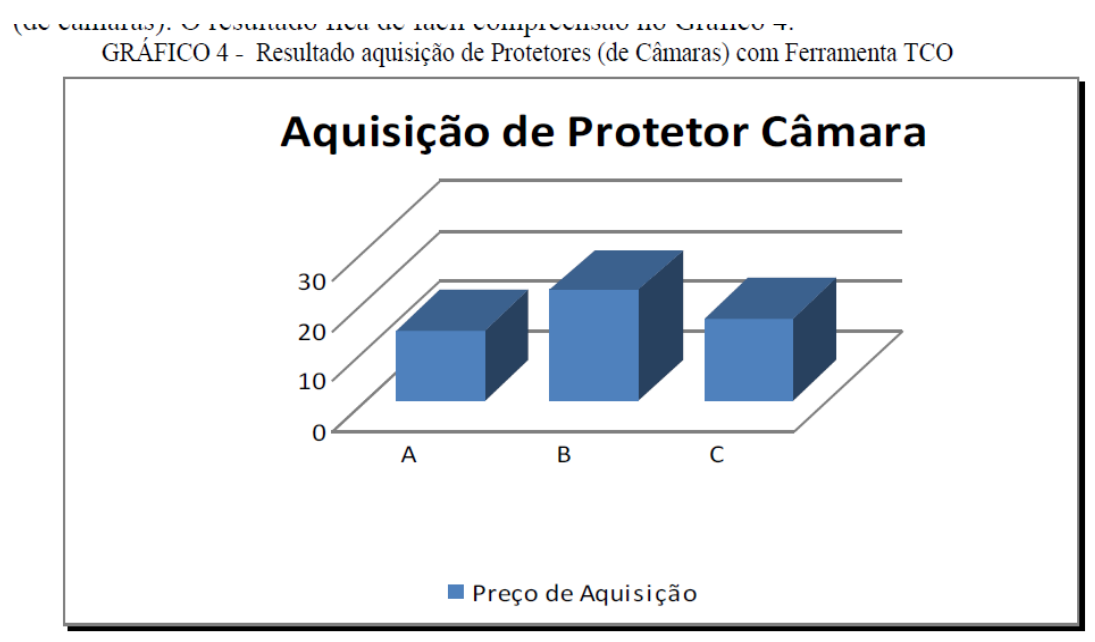

Fonte: Dados da pesquisa.

O fornecedor A possui o melhor preço de aquisição e ainda apresenta o mesmo custo de qualidade dos demais, contando ainda com a mesma durabilidade em horas por pneu. E, assim, o fornecedor A é o mais indicado para compra.

\section{CONSIDERAÇÕES FINAIS}

A obra da Usina Foz do Chapecó conta com uma área/setor encarregada pela compra/aquisição de materiais e bens, denominado setor de Suprimentos, área compras. Neste espaço de trabalho são seis colaboradores que atuam na área de compras, sendo responsáveis pelas aquisições de suprimentos da obra. Para que os referidos colaboradores tenham um procedimento padrão com as outras unidades, são orientados em suas tarefas por Instrução de Trabalho - IT. Cabe salientar que as I.T. têm como objetivo a orientação da metodologia a ser empregada na aquisição de produtos e o comprador sempre deve consultar este documento para saber como proceder em sua prática de compras, bem como para sanar dúvidas. 
A prática tradicional de compras nesta unidade da Empresa/Construtora em estudo consistia na aquisição do material/bem através da cotação de preço, por meio de programa específico.

Inicialmente, a empresa optou por usar o TCO como ferramenta para avaliar custos do setor de informática e, aos poucos, devido ao ótimo resultado em seu uso, foi sendo aperfeiçoada/dinamizada e estruturada para atender toda a área de logística. Assim sendo, o TCO é uma das mais recentes ferramentas para custear a cadeia logística, auxiliando na compreensão dos custos totais de aquisição de um bem ou serviço dos fornecedores, oportunizando a escolha mais viável para a compra/aquisição em questão.

O objetivo do presente estudo foi apresentar a utilização do TCO no processo de compra de uma Construtora de grande porte, referente à obra na Usina Hidrelétrica Foz do Chapecó, visando acompanhar e registrar o uso prático desta ferramenta de gestão estratégica. Antes da aplicação dessa ferramenta, a definição das compras se dava pelo fornecedor que oferecia o preço mais em conta. Com a Ferramenta TCO outros dados foram analisados, como custos de: logística, estoque, qualidade, manutenção e descarte. E, nesse contexto, os materiais/serviços adquiridos foram realmente os mais indicados e viáveis.

\section{REFERÊNCIAS}

ALVES, F. J.; CARDOSO, R. L. (N/C). COQ e TCO: o impacto das decisões de qualidade no custo total de propriedade. Disponível em: $<$ http://www.faf.uerj.br/pastas_prof/ricardo/industrial1/COQ_e_TCO.pdf>. Acesso em: 03/set/2012.

BEZERRA, F. A.; NASCIMENTO, D. A. do. Modelo de Integração entre TCO e ABC. Disponível em: http://www.ucla.edu.ve/DAC/departamentos/coordinaciones/costol/Congresolnternacion aldeCostos./VOL_200511232139(D)/artigos/custos_39.pdf>. Acesso em: 15/jul/2010.

BORNIA, A. C. (2002). Análise Gerencial de custos: Aplicações em empresas modernas. (1 ed.). Porto Alegre: Bookman. 
BORNIA, A. C.; FREIRES, F. G. M. (2005). Uma aplicação do custeio baseado em atividades à gestão dos custos da cadeia de suprimentos. Disponível em: $<$ http://hermes.ucs.br/carvi/cent/dpei/odgracio/ensino/

Gestao\%20Estrategica\%20Custos\%20Unisc\%202005/Artigos/ABCcadeiasuprimento.pd $\mathrm{f}>$. Acesso em: 03/set/2012.

DABBYS, Tom. (N/C). Optimizing Total Cost of Ownership (TCO). Disponível em: <http://www. chemshow.com /newpress/newsitems/ TCO.pdf>. Acesso em: 03/set/2012.

DIAS, M. A. P. (2010). Administração de materiais: princípios, conceitos e gestão. (6 ed.). São Paulo: Atlas.

ECOS, I. Custo Total de Propriedade - TCO: Análise comparativa. Disponível em: <http://www.institutoecos.org.br/br/software/license/tco.htm>. Acesso em: 15/jul/2010.

FLEURY, P. F. (2003). Supply Chain management: conceitos, oportunidades e desafios da Implementação. (1 ed.). São Paulo: Editora Atlas.

GONÇALVES, P. S. (2007). Administração de materiais. (2 ed.). Rio de Janeiro: Elsevier.

IANNI, O. (1999). A sociedade global. (7 ed.). Rio de Janeiro: Civilização Brasileira.

IGNACIO, A. A. V., et al. (2006). O papel do custo total de propriedade (TCO) no gerenciamento da cadeia de suprimentos. XIII SIMPEP - Bauru, SP, Brasil.

KOTLER, P. Tradução: BRANDÃO, A. B. (1998). Administração de Marketing: Análise, planejamento, implementação e controle. (5 ed.). São Paulo: atlas.

KUMAR, U D.; CHATTOPADHYAY, G.; PANNU, H S. (2004). Total Cost of Ownership for railway assets: a case study on boxn wagons of indian railways. Proceedings of the Fifth Asia Pacific Industrial Engineering and Management Systems Conference, 2004. Disponível em: <http://www.apiems.net/ archiveapiems2004/pdf/apiems 2004_8.5.pdf>. Acesso em: 03/set/2012.

LIMA, G. A. S. F. de; LEITÃO, C. R. da Silva. Análise dos recursos da tecnologia de informação para a redução do TCO (Total Cost of Ownership - Custo Total de Propriedade). Disponível em: <http://www.biblioteca.sebrae.com.br/bds/bds.nsf/e88f72ba6056973403256d470064b9d c/de373b9e754c319783256f7100627bf2/\$FILE/An\%C3\%A1lise\%20dos\%20Recursos\% 20de\%20Tecnologia\%20da\%20Informa\%C3\%A7\%C3\%A3o.pdf>. Acesso em: 25/jun/ 2010. 
LUCCA, G.; e Cols. Custos: sua importância na administração. Disponível em: $<\mathrm{http}: / /$ www.pmkb. com.br/artigos-mainmenu-25/151-custos-sua-importianaadministra.html >. Acesso em: 25/jun/2010.

MAUSS, C. V.; MAGALHÃES, J. M.; SOUZA, M. A. de. (2007). A gestão estratégica de custos como instrumento para redução do trade-off entre custo e diferenciação baseada na flexibilidade. ABCustos - Associação Brasileira de Custos. Vol. 2 n. 2, maio/ago. Disponível em: <http://www.unisinos.br/abcustos/_pdf/AC-2007-96.pdf>. Acesso em: 25/jun/2010.

MITSUTANI, C. (2006). TCO - Custo Total de Propriedade: uma ferramenta útil para a área de suprimentos. ATMAN. Disponível em: $<$ http://www.atmanconsultoria.com.br/noticias_publicacoes/detail/7>. Acesso em: 03/set/ 2012.

PACHECO, A. P. R. (2006). Gestão estratégica l: livro didático. (6 ed.). Palhoça (SC): Unisul.

PAES, R.; KLIEMANN NETO, F. J. Discussão crítica sobre sistemas de custeio para avaliação econômica de cadeia de suprimentos. Disponível em: < http://www.abepro.org.br/biblioteca/ENEGEP2007_TR590445_9084.pdf>. Acesso em: 18/abril/2010.

PIOVESAN, A.; TEMPORINI, E. R. Pesquisa exploratória: procedimento metodológico para o estudo de fatores humanos no campo da saúde pública. Disponível em: <http://www.faccamp.br/ revistampe/Publicacoes/1_edicao/Artigo_4_Revisado.pdf>. Acessado em 18/abril/2010.

SANT ANA, Z. A. de; ROCHA, W. (2006). Custo Total de Propriedade: um estudo da sua aplicabilidade à Lei das Licitações. Disponível em: <http://www.congressousp.fipecafi.org/artigos62006/221.pdf>. Acesso em: 03/set/2012.

SILVA, L. M. F. e; VILLAR, A. de M. Discussão sobre as técnicas de avaliação dos custos logísticos para fins de controle gerencial. Disponível em: $<$ http://www.abcustos.org.br/texto/viewpublic?ID_TEXTO=2406>. Acesso em: 25/jun/ 2010.

SOUZA, M. C. de A. F. de; BACIC, M. J.; BERNARDES, J. M. R. (2009). A Gestão Estratégica das Compras como Política para Reduzir Custos. In: Gestão \& Regionalidade. Vol. 25. n. 74. p. 35-47. mai/ago. 
WANTROBA, E. (2007). Avaliação de investimentos em sistemas integrados de gestão empresarial. (Dissertação de Mestrado). Universidade Tecnológica Federal do Paraná UTFPR, Ponta Grossa.

Data de Submissão: 01/11/2012

Data de Aceite: 28/12/2012 